\title{
Water budget and rainfall to runoff processes in a seasonal tropical watershed in northern Thailand
}

\author{
Katsushige Shiraki ${ }^{1}$, Nobuaki Tanaka ${ }^{2}$, Tantasirin Chatchai ${ }^{3}$ and Masakazu Suzuki ${ }^{4}$ \\ ${ }^{1}$ Graduate School of Tokyo University of Agriculture and Technology, Japan \\ ${ }^{2}$ University Forest in Aichi, Graduate School of Agricultural and Life Sciences, The University of Tokyo, Japan \\ ${ }^{3}$ Faculty of Forestry, Kasetsart University, Thailand \\ ${ }^{4}$ Former Graduate School of Agricultural and Life Sciences, The University of Tokyo, Japan
}

\begin{abstract}
:
The water budget and discharge processes in a seasonal tropical watershed were analyzed. The watershed has very stable base stream flows even in the late dry season and very quick direct runoff during rains. A tentative runoff error correction method applying an existing lumped runoff model was proposed in this paper and showed good agreement with the correct runoff error. After correcting runoff data, the annual average rainfall and runoff during the 11 years of 1998-2008 were calculated respectively as 1870.4 $\mathrm{mm}$ and $1229.2 \mathrm{~mm}$. The average annual water loss was $641.2 \mathrm{~mm}$. Distribution measurements of topsoil depth taken using a knocking cone penetration meter showed that this watershed has a deep topsoil layer (5.3 $\mathrm{m}$ average). Groundwater tables are apparent only in the lower area of the watershed. A saturated swamp area is a permanent feature near the weir. Results suggest that the stable base flow in this watershed was generated by return flow of soilwater infiltration into the thick topsoil and fractured bedrock.
\end{abstract}

KEYWORDS Kog Ma watershed; runoff error correction; evergreen forest; ground water table; base flow; top soil depth

\section{INTRODUCTION}

Tropical forests play important roles in the global climate and water cycle (e.g. Choudhury et al., 1998; Malhi et al., 2002) because tropical areas function as huge devices for exchanging solar energy to latent heat flux through evapotranspiration. However, rainfall to runoff processes of tropical regions remain poorly understood (Montanari et al., 2006). This study specifically examined the water budget and rainfall to runoff processes of the Kog Ma D watershed in a mountainous area of northern Thailand. Many studies have been published since 1997 about this watershed, related to hydrological processes such as canopy interception loss (Tanaka et al., 2005), fog drip (Tanaka et al., 2011), seasonal change of tree trunk sap flow (Tanaka et al., 2003), and evapotranspiration together with assumptions of root layer depth (Tanaka et al., 2004). Moreover, the ecosystem features of this watershed were observed precisely during 1966-1980, mainly by Kasetsart University researchers. Those results are summarized in the Kog Ma bulletins, including the monthly water budget (e.g. Chunkao et al., 1981). Therefore, the water budget of this watershed since 1997 is important in terms of elucidating water cycling through combining recent and past research results. As described in this paper, we observed and calculated the water budget of this watershed during 1998-2008 and investigated rainfall to runoff processes by observing the distribution of the topsoil layer depth and changes in the groundwater table. A runoff data error correction method applying an existing lumped runoff model is also proposed to evaluate the continuous water budget.

\section{SITE DESCRIPTION}

The Kog Ma D watershed (N1849' E9854', 1290-1440 $\mathrm{m}$ above sea level) is located along the mountainside of Mt. Doi Pui, about $10 \mathrm{~km}$ west from Chiang Mai city (Figure $1 \mathrm{a}, \mathrm{b})$. This watershed belongs to the university forest of Kasetsart University. The watershed basin area is 8.63 ha (Tanaka et al., 2003). Distinct differentiation can be made between the wet season and dry season (Tanaka et al., 2005): the wet season begins from April, the dry season from November. The vegetation type is an undisturbed hill evergreen forest, with canopy heights of $25-40 \mathrm{~m}$ (Tangtham, 1974). The canopy crown is almost closed. The bedrock geology is weathered granite. At the south ridge of the watershed, an observation tower for micrometeorological research was installed in 1997. The top of the 50 -m-high tower is about $20 \mathrm{~m}$ higher than the canopy. Details of the Kog Ma D watershed location and topography are presented in Figure 1a-c.

\section{OBSERVATION METHODS}

\section{Rainfall and runoff}

The rainfall of the outside forest was measured automatically by tipping bucket type rain gauges $(0.5 \mathrm{~mm}$ water height equivalent per tip; Ohta Keiki Seisakusho Co. Ltd.,

Correspondence to: Katsushige Shiraki, Graduate School of Tokyo University of Agriculture and Technology, 3-5-8 Saiwai-cho, Fuchu-shi, Tokyo 183-8509, Japan. E-mail: shirakik@cc.tuat.ac.jp 

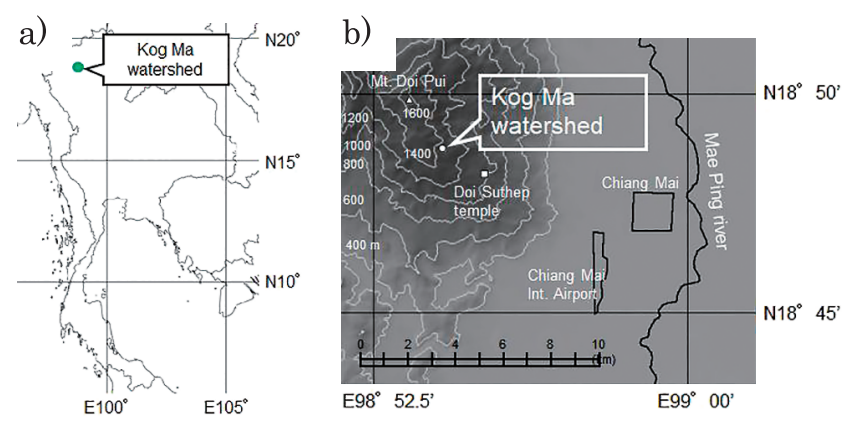

c)

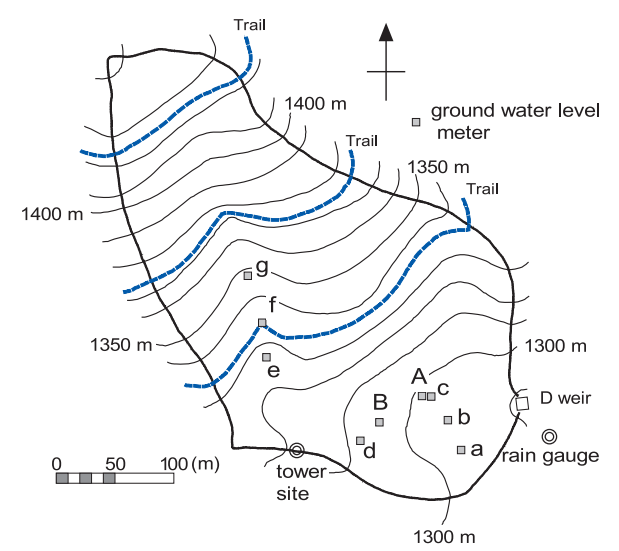

Figure 1. Location and topographic map of the study site: a) location in Thailand; b) location in Chiang Mai city with rough topography; c) topographic map of Kog Ma D watershed with the positions of the tower and the observation points of ground water level (automatic recording A, B and manual observation $\mathrm{a}-\mathrm{g}$ ), rainfall and runoff

Tokyo, Japan) at an open field near the weir (Figure 1c) and at the top of the micro-meteorological tower. The rainfall amounts, which were confirmed carefully with storage type rain gauges, showed good mutual agreement.

Stream water runoff was observed with a 90 degree vshaped weir with weir pool. The relationship between water height at the pool and water discharge flow rate from the weir have been observed several times by manual checking and the H-Q formula has been confirmed. Water heights at the weir pool were measured using an automatic water pressure sensor (KADEC21-MIZU; Kona System Inc., Hokkaido, Japan) and a float level meter with chart paper and pen recording (LR-110WP; Ikeda Keiki Co., Tokyo, Japan). The float level meter data were used for substitution in cases of missing water pressure sensor data.

Rainfall and runoff were recorded every $10 \mathrm{~min}$. The water height equivalent value was calculated.

\section{Ground water level (GWL)}

PVC pipes of 50-mm-diameter with screen (strainer) on their lateral sides were installed by digging wells manually with a hand auger. The bottom of the pipe was set to the topsoil and bedrock boundary, which had been measured in advance with a knocking cone penetrating meter. However, some pipes were unable to reach bedrock because of the soil hardness preventing digging using a hand auger, or because of mud soil with a high water content. The GWL was checked with GWL meters of two types. The maximum GWL meters consisted of a rod with small cups set at $10 \mathrm{~cm}$ intervals installed in the wells. This manual GWL meter can detect the maximum GWL after earlier observation by checking the residual water in cups. We installed 7 maximum GWL meters (named a to g) at the positions shown in Figure 1c. The maximum GWL observation started from April 2005 and were observed every three or four months manually. During the intensive GWL observation period described in a later section, we made manual GWL observation on 29 July 2006 and 29 November 2006. Another type of GWL meter used were automatic water pressure recorders (HM-910-05; Sensez Corp., Tokyo, Japan) with a data logger (CR10X; Campbell Scientific Inc., Utah, USA). We installed 2 automatic GWL meters (named A and B) at the positions shown in Figure 1c. These automatic observations started from July 2004 and were recorded every 10 minutes. In this paper we used the GWL meter data from July to November 2006.

\section{Topsoil depth}

The topsoil distribution was observed with a simplified knocking cone penetrating meter (S06-M, Tsukuba Maruto Co. Ltd., Ibaraki, Japan). This equipment measures soil hardness by manual knocking with impact of a $5 \mathrm{~kg}$ weight from $50 \mathrm{~cm}$ height. The cone at the bottom end penetrates vertically into soil. The knocking count indicates the soil hardness. We defined the topsoil as having hardness of less than 50 counts of knocking per $10 \mathrm{~cm}$ penetration. The topsoil and bedrock boundary was identified clearly by a change in the soil material hardness as well as sound during impact of the weight.

\section{RUNOFF CORRECTION METHOD}

Although rainfall data were acquired during the entire analysis period without error, runoff data were not obtained correctly for some periods because of data recording errors or because of an unusual increase in water height assumed to reflect leaf jamming at the weir. Those erroneous data were substituted with estimated runoff values calculated from a lumped runoff model. We applied the Hydrological Cycle Model reported by Fukushima (1988). This model has been widely used for runoff analysis, including in tropical forested watersheds (e.g. Wakahara et al., 2014). The model consists mainly of 5 connected storage type tanks (tank I to $\mathrm{V}$ in Figure S1a). They represent crown storage tank, base flow tank, quick flow tank and so on. Crown interception loss (Figure S1b), evaporation, base flow and quick flow are calculated separately. We calculated runoff values from rainfall data every hour. We needed 17 parameters to run the model, 9 relating to runoff characteristics and 8 to evapotranspiration. The model parameters were set as shown in Table SI. Those parameters were set using a trial-and-error method to reduce calculation errors from rainfall and runoff data of this watershed. To evaluate the model accuracy, we selected 60 rainfall events for which runoff data were collected without error. The beginning of the rainfall event was chosen before the start of rainfall. The end of the event was determined to be when the runoff rate became the same level as the beginning. The accuracy 
examination is presented in Figure S2. Event rainfall amounts were $12-178 \mathrm{~mm}$. The simulation error for each rainfall event was calculated as shown below.

$$
\text { Error }=\mid \text { Runoff }_{\text {obs }}-\text { Runoff }_{\text {sim }} \mid / \text { Rainfall }_{\text {obs }}
$$

where Runoff obs and Runoff sim are observed and simulated runoff, respectively and Rainfall ${ }_{\text {obs }}$ is observed rainfall.

The average and maximum error between simulated and observed runoff amounts for each rainfall event were, respectively, $1.2 \%$ and $3.4 \%$.

\section{RESULTS}

\section{Runoff correction and water budget}

Eleven years of hydrographs and hyetographs are shown in Figure 2. Runoff correction data and observed raw data are shown on the same graph. The runoff corrections show good agreement with the beginning and ending of the correction period shown as examples in Figure 2 and Figure S3. The total correction period from 1998 to 2008 was 363.7 days (Table I). During these 11 years, there were $9.0 \%$ correction days in all. The summation of rainfall when runoff data were corrected was $2615.5 \mathrm{~mm}$ in total. Analysis described in the previous section revealed at most $3.4 \%$ estimation error to the rainfall while runoff correction. Therefore, the estimated maximum runoff error is calculated as $88.9 \mathrm{~mm}$ (2615.5 mm multiple 3.4\%), which represents $0.66 \%$ of the total runoff from 1998 to 2008
(13521.6 mm). Therefore, we judged that the proposed runoff correction method was adequate for calculating the average water budget in this case. The monthly water budget is shown in Table SII, including data from March 1997 to December 1997.

Although distinct differences between dry and wet seasons are apparent from the hyetograph depicted in Figure 2, the runoff rate was been stable and never zero, even in the late dry season. Instant increases during rainfall were observed. The water budget is presented in Table I. The average annual rainfall and runoff were, respectively, $1870.5 \mathrm{~mm}$ and $1229.2 \mathrm{~mm}$. The average annual loss calculated by subtracting runoff from rainfall was $641.2 \mathrm{~mm}$. The range of annual rainfall was $1262.3-2458.7 \mathrm{~mm}$, although that of runoff was $671.4-1813.3 \mathrm{~mm}$. These annual fluctuations imply a wide range of annual loss, from $154.3 \mathrm{~mm}$ in 2003 to $1035.4 \mathrm{~mm}$ in 1999 . Particularly, the lowest annual loss in 2003 occurred because of large amount of runoff of higher base flow at the beginning of the year produced by the abundant rainfall of the prior year.

\section{Ground water level}

Concentrated GWL observations were conducted from July 2006 to December 2006. Figure 3 shows the change of GWL of A and B obtained using a datalogger, together with rainfall and runoff. As for the maximum GWL meters, the maximum GWL in the period from 29 July to 29 Nov 2006 and the GWL on 29 Nov 2006 are shown in the Table II. These results show the existence of stable groundwater near the weir (GWL A) and intermittent GWL during a very wet
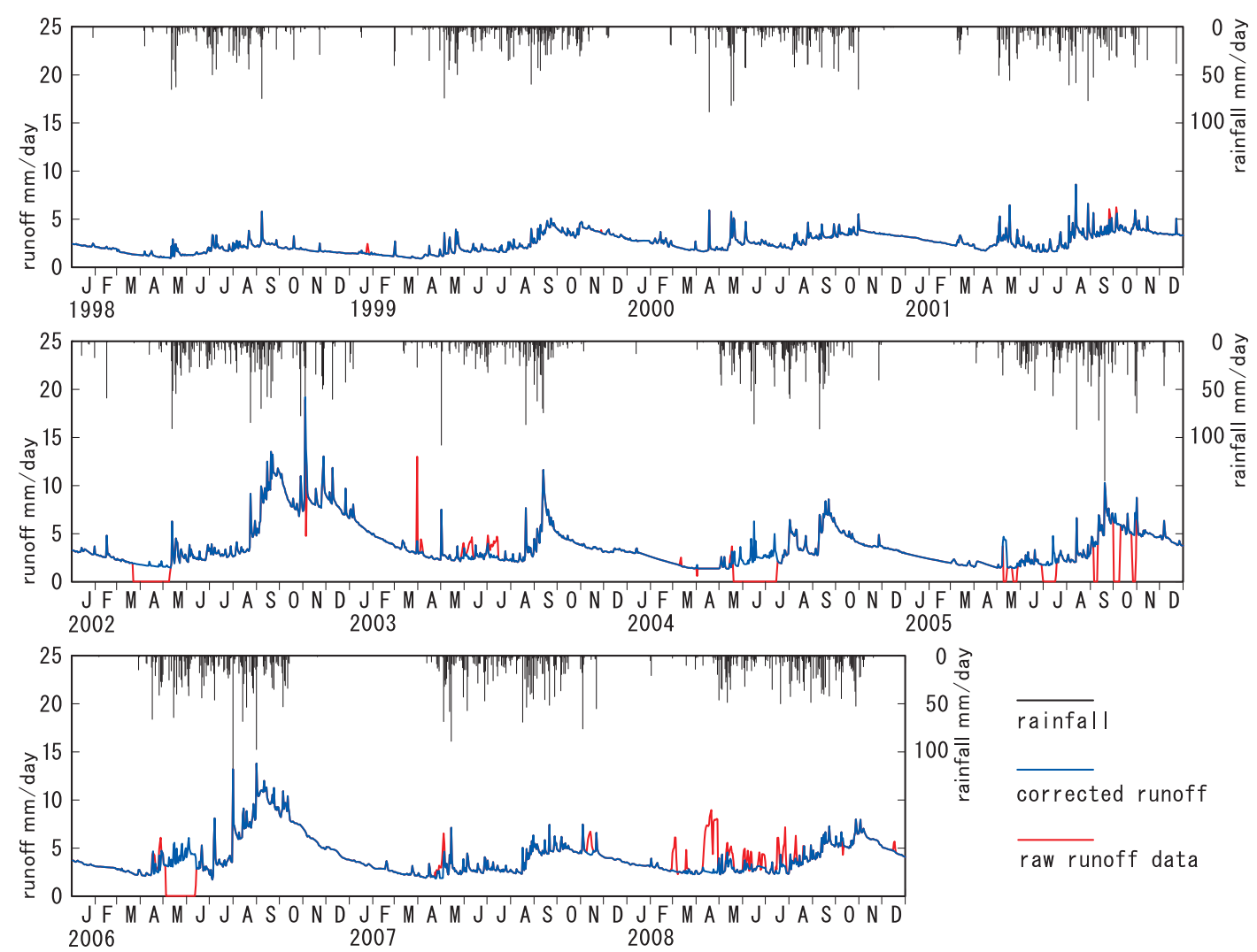

Figure 2. Eleven years hydrograph and hyetograph of Kog Ma D watershed with raw (before corrected) runoff data 
Table I. Eleven year annual, average, and total water budget with aggregation of runoff corrected days during 1997-2008

\begin{tabular}{ccccc}
\hline Year & Rainfall $(\mathrm{mm})$ & Runoff $(\mathrm{mm})$ & Loss $(\mathrm{mm})$ & Correction days \\
\hline 1997 & $(1402.1)$ & $(906.7)$ & $(495.4)$ & $(34.3)$ \\
1998 & 1262.3 & 671.7 & 590.7 & 0.0 \\
1999 & 1883.0 & 847.6 & 1035.4 & 2.8 \\
2000 & 1643.0 & 1023.6 & 619.4 & 0.0 \\
2001 & 1795.8 & 1103.6 & 692.2 & 1.9 \\
2002 & 2458.7 & 1755.4 & 703.3 & 53.5 \\
2003 & 1504.3 & 1350.0 & 154.3 & 34.6 \\
2004 & 1837.2 & 1137.5 & 699.7 & 64.8 \\
2005 & 2045.5 & 1178.0 & 867.5 & 48.9 \\
2006 & 2242.9 & 1813.3 & 429.6 & 52.7 \\
2007 & 2002.0 & 1257.2 & 744.8 & 21.2 \\
2008 & 1900.5 & 1383.7 & 516.8 & 83.3 \\
\hline Total & 20575.2 & 13521.6 & 7053.6 & 363.7 \\
\hline
\end{tabular}

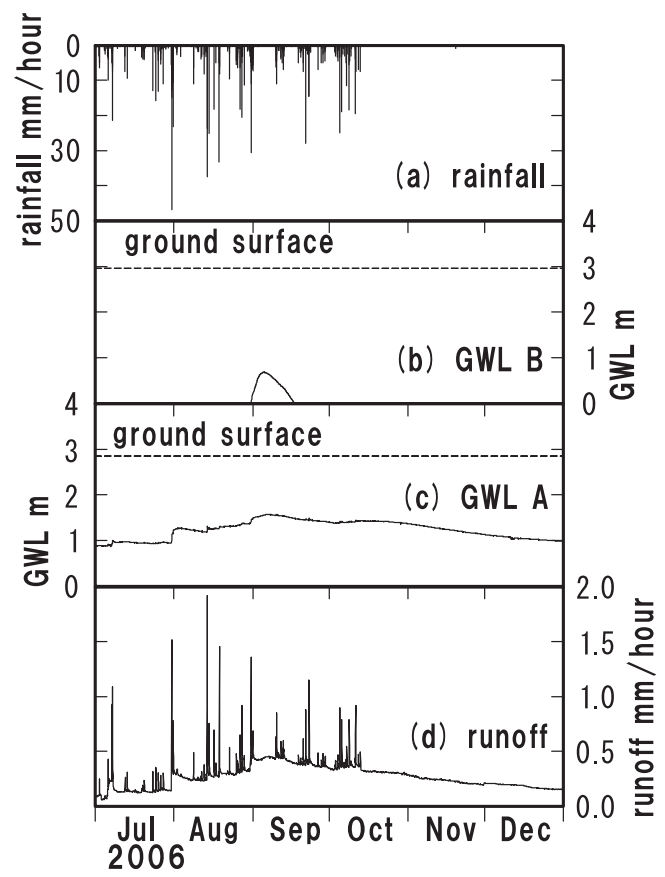

Figure 3. Change of ground water level at concentrated observation period with rainfall and runoff data in 2006

period (GWL B). No GWL or at most $0.2 \mathrm{~m}$ GWL height from the bedrock was observed along the valley higher than GWL e (about $1330 \mathrm{~m}$ above sea level).

\section{Topsoil depth distribution}

The topsoil distribution was calculated from the 59 points surveys shown in Figure 4. The topsoil depth was interpolated every $10 \mathrm{~m}$ to produce the distribution map. The topsoil depth varied from $1.3 \mathrm{~m}$ to $15.9 \mathrm{~m}$. The average topsoil depth was $5.3 \mathrm{~m}$. Although the topsoil along the valley in this study site is comparatively thinner than other
Table II. Specification of GWL observation points and results of concentrated observation in 2006

\begin{tabular}{ccccc}
\hline $\begin{array}{c}\text { Point } \\
\text { name }\end{array}$ & $\begin{array}{c}\text { Topsoil } \\
\text { depth }\end{array}$ & $\begin{array}{c}\text { Installed } \\
\text { depth }\end{array}$ & $\begin{array}{c}\text { Maximum } \\
\text { GWL }^{1)}\end{array}$ & $\begin{array}{c}\text { Instant } \\
\text { GWL }^{2)}\end{array}$ \\
\hline A & 2.85 & 2.85 & & \\
B & 2.95 & 2.78 & sat \\
a & 6.22 & 1.70 & sat $^{3)}$ & 3 \\
b & 3.35 & 3.20 & sat & 2.3 \\
c & 2.55 & 2.55 & sat & 0 \\
d & 2.74 & 2.70 & 0.7 & 0 \\
e & 1.97 & 1.60 & 0 & 0 \\
f & 1.77 & 1.50 & 0 & 0 \\
g & 2.80 & 2.80 & 0.2 & unit (m) \\
\hline \multicolumn{5}{c}{ Maximum GWL during 29 July 2006 to 29 November 2006 } \\
1) Satant GWL at 29 November 2006 \\
3) Saturated up to the ground surface
\end{tabular}

parts, we saw no exposed bedrock inside the study site.

\section{DISCUSSION}

The runoff correction method conducted in this paper using an existing lumped model showed good accordance with actual data (Figure S2). High accuracy of interpolation for the missing runoff data would be expected. This was only a tentative attempt for this study site, other attempts for different watershed are necessary to evaluate the versatility of this method.

The mean annual rainfall at our seasonal tropical watershed $(1870.5 \mathrm{~mm}$, Table I) was identical to or less than humid tropical forest sites in Southeast Asia such as those 


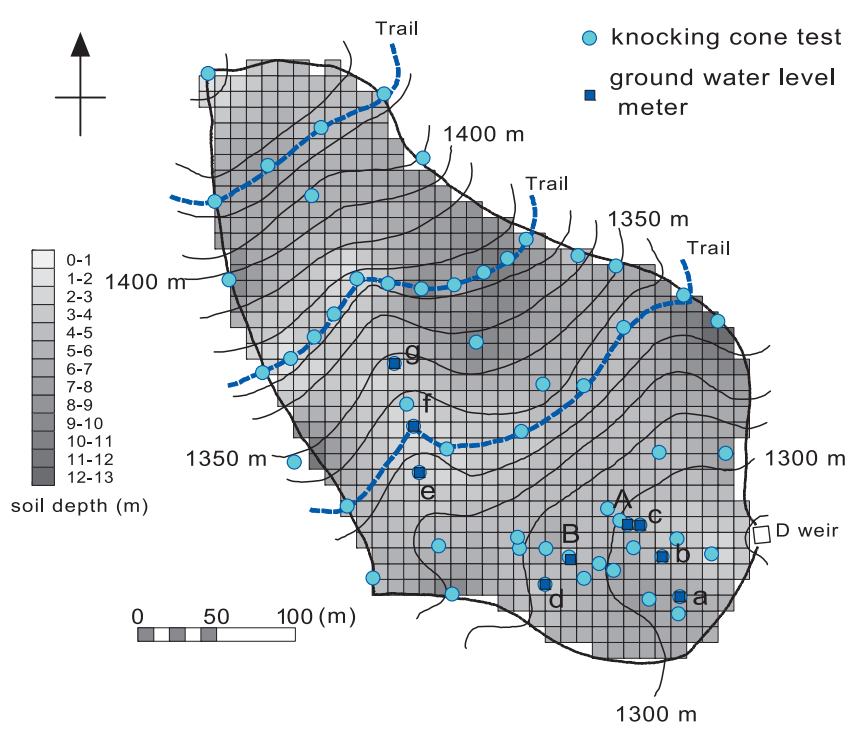

Figure 4. Topsoil depth distribution map with observation points and spatially interpolated map

on the Malaysian Peninsula (1865 mm, Kosugi et al., 2012) and in Borneo Island (2600 mm, Kume et al., 2011). However, the mean annual rainfall in our upland watershed (1290-1440 $\mathrm{m}$ in altitude) was larger than those at tropical seasonal lowland sites on the Indochina Peninsula (1574 $\mathrm{mm}$ on average, Giambelluca et al., 2016). Such an altitudinal variation in annual rainfall was commonly found on the Indochina Peninsula (Kuraji et al., 2001).

The most notable component of our reported water budget may be the small annual mean loss from the watershed (641.2 mm, Table I). Assuming that the loss represents evapotranspiration (ET) from our watershed would allow a comparison of the loss with ET magnitudes from nearby forest sites. The annual loss reported in this study is less than annual ET from nearby lowland forests $(995 \mathrm{~mm}$ on average, Giambelluca et al., 2016), and is much less than annual ET from humid tropical rainforests $(1287 \mathrm{~mm}$, Kosugi et al., 2012; 1323 mm, Kume et al., 2011). Rather, the loss magnitude of the studied watershed is reminiscent of annual ET from forested watersheds in a temperate climate (e.g. 749 mm, Kosugi and Katsuyama, 2007). In summary, the water budget of the studied watershed can be characterized by its relatively high rainfall and low loss/ET as compared with nearby lowland forest sites, implying the importance of similar upland watersheds in this region in regulating water resources for humans downstream.

As for the comparison of water budget analysis conducted in this study site between past (Chunkao et al., 1981) and this paper, Chunkao et al. (1981) reported that the 15 years water budget from 1966 to 1980 was $2084.1 \mathrm{~mm}$ of mean annual rainfall and $1378.2 \mathrm{~mm}$ of mean runoff, therefore $705.9 \mathrm{~mm}$ annual loss. This suggests a decreasing tendency in both mean annual rainfall and runoff. The annual loss also showed a decreasing tendency, by $65 \mathrm{~mm}$.

A specific feature of runoff characteristics of this watershed is a stable base flow, even in the late dry season. The thick topsoil layer functions to maintain high soil water capacity. A simulation of root depth effects by Tanaka et al.
(2004) estimated that 4-5 $\mathrm{m}$ rooting depth was necessary to simulate an transpiration peak in the late dry season. These simulation results show good agreement with the observed thick topsoil depth (5.3 $\mathrm{m}$ average).

Very rare GWL occurrence in the middle and upper areas of this watershed also suggest deeper infiltration of soil water into bedrock. Therefore, fractured bedrock is assumed to exist below the topsoil layer. However, constant GWL and a swamp area exist near the weir, which indicates impermeable bedrock below the fractured bedrock. Return flow from the impermeable bedrock is assumed to create the stable base flow in this watershed (Figure S4). Unsaturated vertical flow of the thick topsoil and fractured bedrock is assumed to generate a delayed water flow sufficient to retain the rainfall during the wet season for later discharge in the late dry season. Constantly saturated areas and nearly saturated areas with constant GWL near the weir can be a source of quick flow during rains. The ratio of quick flow of this watershed was calculated as 3-5\% (no figure) of rainfall amounts for each rainfall event; this value shows good agreement with the ratio of swamp area to the total watershed area, which is estimated as about $3 \%$.

We were unable to clarify whether the characteristics of rainfall to runoff process of this watershed are representative of evergreen forests in seasonal tropical forests, or not. Further accumulation of research results is necessary to clarify the rainfall-runoff processes in these evergreen tropical forests.

\section{CONCLUSION}

We precisely observed and calculated the water budget for a seasonal tropical forested watershed using 11 years of data. The actual states of rainfall to runoff processes in the Kog Ma D watershed were analyzed. Very stable base flows, a principal characteristic of this watershed, are presumably generated by a thick topsoil layer and fractured bedrock. We also proposed a tentative method for runoff correction of erroneous or missing data applying an existing lumped runoff simulation model. The runoff correction limits error to $0.66 \%$, at most, compared to the total runoff in this case.

\section{ACKNOWLEDGMENTS}

A part of this work was supported by JSPS KAKENHI Grant Number JP16H02556.

\section{SUPPLEMENTS}

Figure S1. Structure of Hydrological Cycle Model (Fukushima, 1988): a) main model structure, b) canopy interception loss model

Figure S2. Accuracy check for the correction of runoff with a Hydrological Cycle Model; relationship between observed and simulated event runoff

Figure S3. Runoff correction examples: a) assumed leaf jamming error (short period), b) assumed leaf jamming error (long period), and c) missing data (long period) 
Figure S4. Illustration of soil water movement in the Kog Ma D watershed

Table SI. Some parameters of the Hydrological Cycle Model (Fukushima, 1988)

Table SII. Monthly water budget from March 1997 to December 2008

\section{REFERENCES}

Choudhury BJ, Di Girolamo NE, Susskind J, Darnell WL, Gupta SK, Asrar G. 1998. A biophysical process-based estimate of global land surface evaporation using satellite and ancillary data II. Regional and global patterns of seasonal and annual variations. Journal of Hydrology 205: 186-204. DOI: 10.1016/S0022-1694(97)00149-2.

Chunkao K, Tangtham N, Boonyawat S, Niyom W. 1981. Watershed management research on mountainous land, 15-Year Tentative Rep., 1966-1980, Department of Conservation Faculty of Forestry Kasetsart University, Bangkok, Thailand; 62 (in Thai with English abstract).

Fukushima Y. 1988. A model of river flow forecasting for a small forested mountain catchment. Hydrological Processes 2: 167-185. DOI: 10.1002/hyp.3360020207.

Giambelluca TW, Mudd RG, Liu W, Ziegler AD, Kobayashi N, Kumagai T, Miyazawa Y, Lim TK, Huang M, Fox J, Yin S, Mak SV, Kasemsap P. 2016. Evapotranspiration of rubber (Hevea brasiliensis) cultivated at two plantation sites in Southeast Asia. Water Resources Research 52: 660-679. DOI: $10.1002 / 2015$ WR017755.

Kosugi Y, Katsuyama M. 2007. Evapotranspiration over a Japanese cypress forest. II. Comparison of the eddy covariance and water budget methods. Journal of Hydrology 334: 305311. DOI: 10.1016/j.jhydrol.2006.05.025.

Kosugi Y, Takanashi S, Tani M, Ohkubo S, Matsuo N, Itoh M, Noguchi S, Abdul Rahim N. 2012. Effect of inter-annual climate variability on evapotranspiration and canopy $\mathrm{CO}_{2}$ exchange of a tropical rainforest in Peninsular Malaysia. Journal of Forest Research 17: 227-240. DOI: 10.1007/ s10310-010-0235-4.

Kume T, Tanaka N, Kuraji K, Komatsu H, Yoshifuji N, Saitoh T, Suzuki M, Kumagai T. 2011. Ten-year evapotranspiration estimates in a Bornean tropical rainforest. Agricultural and
Forest Meteorology 151: 1183-1192. DOI: 10/1016/j. agrformet.2011.04.005.

Kuraji K, Punyatrong K, Suzuki M. 2001. Altitudinal increase in rainfall in Mae Chaem watershed, Thailand. Journal of the Meteorological Society of Japan 79: 353-363. DOI: 10.2151/jmsj.79.353.

Malhi Y, Pegoraro E, Nobre AD, Pereira MGP, Grace J, Culf AD, Clement R. 2002. Energy and water dynamics of a central Amazonian rain forest. Journal of Geophysical Research 107: 8061. DOI: 10.1029/2001JD000623.

Montanari L, Sivapalan M, Montanari A. 2006. Investigation of dominant hydrological processes in a tropical catchment in a monsoonal climate via the downward approach. Hydrology and Earth System Sciences 10: 769-782. DOI: 10.5194/ hess-10-769-2006.

Tanaka K, Takizawa H, Tanaka N, Kosaka I, Yoshifuji N, Tantasirin C, Piman S, Suzuki M, Tangtham N. 2003. Transpiration peak over a hill evergreen forest in northern Thailand in the late dry season: Assessing the seasonal changes in evapotranspiration using a multilayer model. Journal of Geophysical Research 108. DOI: 10.1029/2002JD003028.

Tanaka K, Takizawa H, Kume T, Xu J, Tantasirin C, Suzuki M. 2004. Impact of rooting depth and soil hydraulic properties on the transpiration peak of an evergreen forest in northern Thailand in the late dry season. Journal of Geophysical Research 109. DOI: 1029/2004JD004865.

Tanaka N, Tantasirin C, Kuraji K, Suzuki M, Tangtham N. 2005. Inter-annual variation in rainfall interception at a hill evergreen forest in Northern Thailand. Bulletin of the Tokyo University Forest 113: 11-44.

Tanaka N, Kuraji K, Tantasirin C, Takizawa H, Tangtham N, Suzuki M. 2011. Relationships between rainfall, fog and throughfall at a hill evergreen forest site in northern Thailand. Hydrological Processes 25: 384-391. DOI: 10.1002/ hyp. 7729 .

Tangtham N. 1974. Preliminary study of the ecosystem of hill evergreen forest in northern Thailand. PhD Thesis, Pennsylvania State University, University Park, Pennsylvania, USA; 64.

Wakahara T, Shiraki K, Suzuki M. 2014. Comparison of runoff characteristics of two adjacent basins in a tropical rainforest using a modified hydrologic cycle model with outflow. Hydrological Processes 28: 509-520. DOI: 10.1002/hyp. 9602. 